Boise State University

ScholarWorks

8-1-2004

\title{
How We Think About and Prepare to Teach Physics
}

Dewey I. Dykstra

Boise State University 


\title{
How we think about and prepare to teach physics
}

\author{
Dewey I. Dykstra, Jr. \\ Physics Department, Boise State University, Boise, ID 83723-1570
}

\begin{abstract}
We have been preparing physics teachers in the same manner for many decades. Yet, physics education research reveals for some observers disturbing evidence of little or no change in understanding the phenomena occurs as a direct result of physics instruction from elementary school through the college years. The apparent compatibility between these learning results and prevailing paradigm enables the construction of a description the paradigm. If it can be demonstrated that there is even just one alternative paradigm from which powerful alternative pedagogical practice is derived, are we not obligated to change how we prepare to teach physics?
\end{abstract}

\section{INTRODUCTION}

“... a physics major has to be trained to use today's physics whereas a physics teacher has to be trained to see a development of physical theories in ... students' minds. "1

In recent decades those interested in science teaching and learning have investigated very carefully science learning. The rise in attention to an explanation of the origins of knowledge and evidence supporting the explanation has inspired a focus in physics education research (PER) on students' conceptions of the phenomena studied in physics.

\section{EVIDENCE ABOUNDS...}

The "modern" era of this research began in the 1970's, but articles on students' conceptions about phenomena have been uncovered as far back as 1903 . In the 1980's several bibliographic efforts on students' conceptions were coalesced into one bibliography. ${ }^{2}$ Maintained by Reinders Duit at the University of Kiel, it now contains 6,314 entries.

This body of research supports one of the more robust findings in educational research:

The general outcome of science instruction is no significant change in students' conceptions of the phenomena studied in the classroom.
It is not possible in the space available to do more than show a few examples and invite the reader to consult the bibliography: ${ }^{2}$

Kinematics-acceleration: "The conceptual difficulties with acceleration that were encountered by the students in our study appeared to be very persistent. Often, ... the procedures used by a particular student were the same before and after instruction. ... A significant number of students from a wide variety of courses confused the concepts of velocity and acceleration. ... At the completion of instruction, fewer than half of the students demonstrated sufficient qualitative understanding of acceleration as a ratio to be able to apply this concept in a real situation." ${ }^{3}$

Electric circuits: "We have examined students' explanations of an extremely simple electric circuit, one that involved only three major components. ...many students were unable to interpret the circuit correctly. ... One suspects, therefore, that a significant proportion of students in physics courses will have this type of difficulty. ...the misconception persisted in some students who had been through a calculus-based course in electricity which included five experiments on electric circuits."

\section{RECENT EXAMPLE IN DETAIL}

To sample more of the population in order to find out how widespread these conceptions might be, multiple-choice format diagnostic instruments were developed. One diagnostic is the Force and Motion 
Conceptual Evaluation (FMCE). ${ }^{5}$ This diagnostic is designed to discern the nature of a student's conception or "physical theory" concerning the explanation of motion in terms of force, not merely to determine whether a student knows the "correct" answer. $^{6}$

An analysis of the FMCE responses of students in standard algebra-trig-level and calculus-level introductory students from state and private institutions of higher education across the U.S.A. over a dozen years was conducted by Dykstra ${ }^{7,8}$. The analysis of this data was guided by that of Thornton. ${ }^{6}$

Using a more coarse scale of analysis than Thornton, two keys to the responses in the FMCE were generated. One key is the set of choices consistent with a person-on-the-street (pots) explanation of motion in terms of force, i.e., velocity goes as the force. The other key is a set of choices consistent with a Newtonian-like $(N)$ explanation of force, i.e., acceleration goes as the net force. Comparing a student's responses to the each key yields a score in the range of $0-15$ indicating the degree to which the student's responses match the corresponding explanation of motion in terms of force.

TABLE 1: Results of Traditional Instruction

Traditional, Content-Driven Instruction Algebra-Trig Level Intro Physics

\begin{tabular}{|c|c|c|c|c|c|c|c|c|c|c|}
\hline \multirow[b]{3}{*}{ Year } & \multirow[b]{3}{*}{ Term } & \multirow[b]{3}{*}{$\mathrm{n}$} & \multirow{2}{*}{\multicolumn{2}{|c|}{$\begin{array}{c}\text { Effect Size } \\
(\text { st dev })\end{array}$}} & \multicolumn{2}{|c|}{ Normalized } & \multicolumn{4}{|c|}{ Averages } \\
\hline & & & & & Gain & Loss & \multicolumn{2}{|c|}{ Pre } & \multicolumn{2}{|c|}{ Post } \\
\hline & & & $N$ & pots & $<\mathrm{g}\rangle$ & $<\mathrm{L}>$ & pots & $N$ & pots & $\mathrm{N}$ \\
\hline \multicolumn{11}{|c|}{ West Coast Public Univ. A } \\
\hline 1990 & & 99 & 0.59 & -0.47 & 0.14 & -0.09 & 10.1 & 1.5 & 8.5 & 3.3 \\
\hline \multicolumn{11}{|c|}{ "Prairie State" Public Univ. } \\
\hline 2002 & SP & 112 & 0.66 & -0.40 & 0.13 & -0.06 & 10.3 & 0.9 & 9.0 & 2.7 \\
\hline \multicolumn{11}{|c|}{ Calculus Level Intro Physics } \\
\hline \multicolumn{11}{|c|}{ North East State Public Univ. } \\
\hline 1998 & & 72 & 0.47 & -0.30 & 0.15 & -0.06 & 9.6 & 1.7 & 8.5 & 3.5 \\
\hline \multicolumn{11}{|c|}{ West Coast Public Univ. B } \\
\hline 1999 & W & 87 & 0.60 & -0.62 & 0.22 & -0.30 & 9.3 & 2.6 & 6.5 & 5.4 \\
\hline 1999 & SP & 73 & 0.38 & -0.36 & 0.12 & -0.01 & 9.1 & 2.3 & 7.6 & 4.0 \\
\hline 2000 & SP & 115 & 0.59 & -0.50 & 0.15 & -0.10 & 9.2 & 2.4 & 7.2 & 4.8 \\
\hline \multicolumn{11}{|c|}{ West Coast Private Univ. } \\
\hline 2000 & SP & 38 & 0.54 & -0.08 & 0.09 & 0.05 & 9.8 & 0.6 & 9.6 & 1.9 \\
\hline
\end{tabular}

TABLE 1 gives some of the results of this analysis. Effect size is the shift between the pre and post scores in units of pooled standard deviations. Normalized gain is the fraction of the possible increase in the $N$ score. Normalized loss is the fraction of the possible decrease in pots score.

From the average pre-scores in TABLE 1 these typical students, who have all had instruction on motion and force at least once before, are still answering in a manner consistent with the pots explanation. In the whole sample of students in this on-going study, now numbering nearly 1150 students, there have been only 5 whose pre-responses earned an $N$ score high enough to be convinced they were using a Newtonian-like view of motion and force. With the second or third treatment of traditional, content-driven instruction in this study, while there is some change, the change is still very small after the semester's instruction by $\mathrm{Ph}$. D. physicists.

\section{EXPLAINING THE EVIDENCE}

The prevailing paradigm apparently accounts for this long-standing state of affairs. If not, physics teaching and physics teacher preparation would have changed long ago. This enables us to develop descriptions of the standard paradigm on a phenomenological basis.

In the prevailing paradigm, the nature of the enterprise of physics teaching can be characterized in the following way $^{7}$ :

Physics teaching is the presentation of the official canon of physics by approved methods for the benefit of those who deserve it.

As with other core elements of a paradigm, it is taken as given and so, goes unchallenged.

The word "deserving" means that a student has met two criteria in order to "learn" physics. (1) The student must be capable. Not all people are capable of this feat because "physics is hard." (2) The student must work diligently. Failure to meet one of these two criteria is one of the general explanations why most students do not understand physics at the end of the semester. The other general explanation relates to the teaching of physics.

In this enterprise, in order to prepare to teach physics first one must know the official canon. Girded with the official canon, one needs be able to apply approved methods of presentation. Thus, degree programs for the preparation of physics are designed. Take the standard degree program in physics. Trim a little away to make room for the methods class and a chance to practice the methods in student teaching. There is no attention to the necessary fundamental issue Niedderer indicates the preparation of a physics teacher: the ability "...to see a development of physical theories in ...students' minds."

If the teacher presents the canon properly, the "deserving" student will "get" it. The canon is a commodity transferable from teacher to student under suitable circumstances. This is founded on a realist view of the nature of knowledge which postulates that: "...the objective existence of physical reality that can be known to our minds... with an ever growing 
precision by the subtle play of theory and experiment." The nature of knowledge, a taken as given foundational aspect of this paradigm, is whatever it is, independent of human beings. By clear implication this knowledge can exist outside the mind in order to be transmitted by physical means from teacher to student and in order to have an independent existence.

Having presented the established canon by accepted methods, the responsibility of the teacher has been met. If the necessary characteristics for student success satisfactorily account for the "learning" outcomes of physics teaching, there is no need to look any deeper. Thus, we can understand the lack of research in students' understandings over literally centuries until recent decades and resistance to the findings of such research. No wonder that the findings from PER have had so little effect on physics teaching. In the standard paradigm, we are apparently doing about as good a job as possible at physics teaching.

\section{AN ALTERNATIVE PARADIGM}

In the standard paradigm TABLE 1 is an example of what we can expect of the most deserving students, the science and engineering majors, in courses given by instructors who know the established canon and use approved methods. It should then be the case that students less likely to be "deserving" would not be able to show any more change in understanding than the science and engineering majors.

Let us take a look at students more likely to be the "less deserving." The first six rows of results in TABLE 2 are from non-science, non-engineering majors in a course that satisfies general university requirements in science. The data was collected using the FMCE and analyzed in the same way. These students experienced a pedagogical practice rooted in a different paradigm. Clearly, the standard paradigm belief that there is a limited set of "deserving" students is contradicted by these results. The instructional materials used were developed for the Motion and Force Modules of the Powerful Ideas in Physical Science (PIPS) Project of the American Association of Physics Teachers. ${ }^{10}$

Comparing TABLE 1 and TABLE 2, it is quite clear that the shift in the response patterns is considerably greater. The revised PIPS instruction average effect size of 2.5 standard deviations and $61 \%$ normalized gain in the $N$ scores for the college students far exceeds that of the science and engineering majors in TABLE 1 . Clearly the notion that the status quo in physics teaching is about as good as we can expect is totally discredited by this repeated example of a different pedagogy based on an alternative paradigm.

TABLE 2: Results of Alternative Paradigm Instruction

Student Understanding-Driven Instruction Conceptual Physics--Standard PIPS Instruction

\begin{tabular}{|c|c|c|c|c|c|c|c|c|}
\hline \multirow[b]{3}{*}{ Year Term $\mathrm{n}$} & \multirow{2}{*}{\multicolumn{2}{|c|}{$\begin{array}{c}\text { Effect Size } \\
\text { (st dev) }\end{array}$}} & \multirow{3}{*}{\multicolumn{2}{|c|}{$\begin{array}{l}\text { Normalized } \\
\text { Gain Loss } \\
<\mathrm{g}>\quad<\mathrm{L}>\end{array}$}} & \multicolumn{4}{|c|}{ Averages } \\
\hline & & & & & \multicolumn{2}{|c|}{ Pre } & \multicolumn{2}{|c|}{ Post } \\
\hline & & pots & & & pots & $N$ & pots & $\mathrm{N}$ \\
\hline \multicolumn{9}{|c|}{ Boise State University } \\
\hline 1999 SP 97 & 2.00 & -1.90 & 0.49 & -0.68 & 9.4 & 0.9 & 3.0 & 7.8 \\
\hline 1999 FL 93 & 1.78 & -1.80 & 0.48 & -0.63 & & 0.8 & 3.6 & 7.6 \\
\hline \multicolumn{9}{|c|}{ Conceptual Physics--revised PIPS Instruction } \\
\hline \multicolumn{3}{|c|}{ Boise State University } & & & & & & \\
\hline 2000 FL 90 & 2.50 & -2.20 & 0.59 & -0.66 & 9.3 & 0.8 & 2.5 & 9.2 \\
\hline 2001 SP 87 & 2.40 & -2.40 & 0.62 & -0.74 & 9.8 & 0.8 & 2.2 & 9.6 \\
\hline 2002 FL 66 & 2.62 & -2.19 & 0.57 & -0.72 & 9.4 & 0.8 & 2.2 & 8.8 \\
\hline $2004 \quad$ SP $\quad 69$ & 2.31 & -1.85 & 0.67 & -0.78 & 7.9 & 2.2 & 1.8 & 10.8 \\
\hline \multicolumn{9}{|c|}{ High School Level--Standard PIPS Instruction } \\
\hline 2001 FLa 23 & 6.30 & -5.40 & 0.89 & -0.95 & 11.3 & 0.6 & 0.6 & 13.3 \\
\hline 2001 FLb 24 & 6.10 & -3.70 & 0.86 & -0.93 & 10.6 & 0.9 & 0.8 & 13.1 \\
\hline
\end{tabular}

\section{PREPARING TEACHERS IN AN ALTERNATIVE PARADIGM}

We arrive back at Niedderer's statement: " $a$ physics teacher has to be trained to see a development of physical theories in ...students' minds." "The phenomena studied in physics courses are what the physical theories are about. Sadly, most physics courses are not studies of the phenomena, but drilland-practice at the canon. They do not train a person to see the development of explanatory knowledge in her students' minds.

A physics teacher candidate needs to be metacognitive about the development of his own explanatory knowledge and to interact with others about this meta-cognition. The future teacher needs to observe students to discern evidence of their explanatory knowledge. The teacher candidate should become familiar with the PER research literature. The physics teacher candidate should also practice strategies intended to maximize the chances of disequilibration in students and to facilitate their development of new explanatory schemes. Also, the teacher candidates should study the historical development of physical theories and the philosophical analysis of the nature of knowledge and its development.

In this alternative paradigm, the emphasis is on the nature of understanding. The students' understandings, 
physical theories in student minds, are the primary objects of study and manipulation; not the phenomena, the apparatus, lab skills, mathematics or the canon. The teacher must be able to construct in her own mind effective models of the students' understandings and to pick examples of experience the students will decide are challenges to their existing understandings.

\section{PREPARING PHYSICS TEACHERS}

To meet the challenge, we need to develop courses and degree programs to bring out the ability to see the development of physical theories in students' minds. Two examples of courses to this end do exist.

A course sequence with an intense focus on the development of more powerful understanding and the ability to clearly, rigorously describe experiences within this understanding is offered at the University of Washington by the Physics Education Group (PEG). ${ }^{11}$ The course sequence is Phys 407 \& Phys 408: Physics by Inquiry. ${ }^{12-13}$

At Boise State University a course is being developed to introduce teacher candidates to the "the development of physical theories" in the minds of students. The course, PHYSCI 497/597: Alternative Conceptions in Science, engages teacher candidates in two major activities. Teacher candidates study articles in the bibliography ${ }^{2}$ to develop a catalog of descriptions of conceptions their future students are likely to have when they come to class. They also study student work: responses on diagnostics, posters developed by students describing their ideas, writing assignments, electronic course discussions, etc. to discern evidence of student conceptions and of change in their theories.

\section{CONCLUSION}

Conventional, content-driven physics instruction fails at leaving students with deeper understandings of the phenomena they study. Student-understanding driven pedagogy does result in significant change in student understanding. Its existence places on us the burden of responding in our own practices and in how we prepare the physics teachers who come after us.

We need to assist physics teachers at developing the skills, habits, and points of view that enable the ability "to see the development of physical theories" in the minds of students. Courses to this end are being developed. More such courses need to be established and built into whole degree programs, not only for physics teachers, but also for all teachers.

\section{ACKNOWLEDGMENTS}

Without students willing to share their ideas none of this work nor the data would have been possible. Without the opportunity to interact with the PER community what quality there is in this work would be seriously diminished. On several occasions funding from NSF provided support as some of the data was collected and ideas herein were formulated.

\section{REFERENCES}

1. Niedderer, H., "What Research can Contribute to the Improvement of Classroom Teaching," in Proceedings of the International Conference on Physics Teachers' Education, Dortmund, University of Dortmund, 1992, p. 151. Available at url: <http://didaktik.physik.unibremen.de/niedderer/download/8dortmph.pdf>

2. Duit, R., Students and Teachers Conceptions in Science. url: $<\mathrm{http}: / /$ www.ipn.unikiel.de/aktuell/stcse/stcse.html> (2004)

3. Trowbridge, D. \& McDermott, L. American Journal of Physics 48(3), 242 - 253 (1981).

4. Fredette, N. \& Clement, J., Journal College Science Teaching 10(5), $280-285$ (1981).

5. Thornton, R. \& Sokoloff, D. American Journal of Physics 66(4), 338 - 352, (1998).

6. Thornton, R., "Conceptual Dynamics: Following changing student views of force and motion," in The Changing Role of Physics Departments in Modern Universities: Proceedings of ICUPE, edited by E. F. Redish \& J. S. Rigden, College Park, MD: American Institute of Physics, 1997. Abstract online at http://ase.tufts.edu/csmt/html/abstracts/icupe_cd.html.

7. Dykstra, D., "Why teach kinematics?: An examination of the teaching of kinematics and force, Part I" submitted to the Physics Education Research Supplement of the American Journal of Physics, (2002). Available at url: $<$ http://www.boisestate.edu/physics/dykstra/WTK1.pdf $>$

8. Dykstra, D., "Why teach kinematics?: An examination of the teaching of kinematics and force, Part II" submitted to the Physics Education Research Supplement of the American Journal of Physics, (2002). Available at url: $<$ http://www.boisestate.edu/physics/dykstra/WTK2.pdf $>$

9. de la Torre, A. \& Zamorano, R., American Journal of Physics 69 (2), 103 (2001)

10. American Association of Physics Teachers, Powerful Ideas in Physical Science-A Model Course, College Park, AAPT (2002)

11. PEG, <http://www.phys.washington.edu/groups/peg/> (2004)

12. McDermott, L, Am. J. Phys. 69(11), 1127 - 1137 (2001). Downloadable from

$<$ http://www.phys.washington.edu/groups/peg/oersted.ht $\mathrm{ml}>$

13. PEG,

$<$ http://www.phys.washington.edu/groups/peg/pubsa.htm $1>(2004)$ 